\title{
Russia delays Lake Vostok drill
}

\section{ST PETERSBURG}

Russia is postponing its controversial plans to drill into Antarctica’s sub-glacial Lake Vostok. Russian scientists now hope to start probing the pristine environment almost 4,000 metres below the East Antarctic ice sheet in the 2009-10 drilling season.

"For technical and legal reasons, penetration is not yet possible this coming season," Valery Lukin, director of the Russian Antarctic Expedition, told Nature last week at a meeting in St Petersburg of the Scientific Committee on Antarctic Research (SCAR).

Drilling, which got stuck last year in the accretion ice - lake water frozen onto the bottom of the ice sheet - some 80 metres above the lake surface, will be resumed in November, he says. But before attempting the final entry into the lake, Russia will submit a finalized environmental evaluation to the 46 members of the Antarctic Treaty at their April 2009 meeting in Baltimore, Maryland. The evaluation contains responses to concerns raised by scientists who are fearful that the drilling will contaminate the uniquely unspoiled environment.

Stopping the drill 30 metres or so above the lake surface, as SCAR recommended more than ten years ago, is not seen as an option: the Vostok project is central to the whole Russian Antarctic programme, and is a matter of national importance similar to the race to the Moon in the 1960 s, says Lukin. "We will definitely drill into the lake in 2010, with Russian-developed

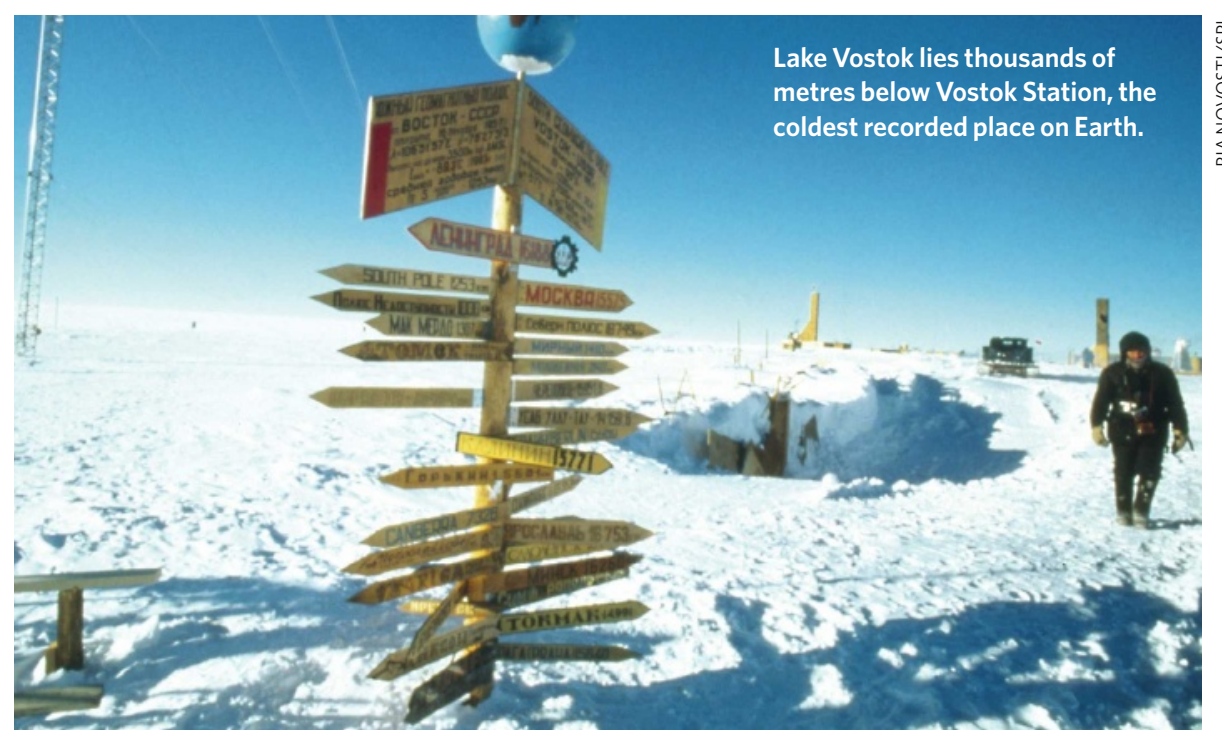

drilling technology," he says. "But most importantly, we'll do so in full compliance with all the rules of national and international law."

The legitimacy of the drilling is undisputed, but concerns remain about possible biological and chemical contamination of the lake. "The Russians have met their obligations under the Antarctic Treaty," says Chuck Kennicutt, the US delegate to, and a vice-president of, SCAR. "Ideally, they would first test the drilling technology at a less sensitive location. But there is no way of preventing them from going ahead."

Lake Vostok lies 1,200 kilometres inland, beneath one of Russia's Antarctic stations, in one of the coldest parts of the continent. It is the largest and deepest of the 150 or so subglacial freshwater lakes that have been discovered by radar imagery beneath the Antarctic ice sheet. Similar in size to Lake Ontario, it contains more than 5,000 cubic kilometres of up to 1-millionyear-old water. This water is super-saturated with oxygen and is liquid below its normal freezing point, because of the high pressure beneath the ice. Scientists believe that the sealed lake, if it is able to support microbial life, might offer a unique window into ancient DNA.

\section{Pakistan finds two radioactive containers}

When Pakistan ran an advertisement campaign last year telling citizens what to do if they stumbled upon radioactive material, it raised eyebrows in the West. Now Pakistani authorities have discovered two radioactive containers of unknown origin, bringing into further doubt their ability to keep track of nuclear material.

The sealed containers were dug up from under a workshop by staff at the state-run Oil and Gas Development Corporation in Karachi. The Pakistan Nuclear Regulatory Authority (PNRA) categorized them as 'orphan sources' last week, as the oil company have no record of where they came from.

It's not unheard of for misplaced radioactive sources, for example those originally used in industrial processes, to pop up from time to time. These orphan sources usually cause little consternation in the international community; but in this case, there are added worries over their origin and the security of Pakistan's nuclear programme. “Pakistan doesn't have a good record for keeping track of where radioactive materials are going," says Peter Crail, a research analyst at the Arms Control Association, a non-profit organization in Washington DC. “The 1990 s saw a lot of illicit trafficking of radioactive materials between this region of Asia and eastern Europe."

While there has been a clampdown on trafficking since 2000, such material could pose a threat if it were to fall into the wrong hands and be used for weapons, says Crail. Last year's ad campaign launched by the Pakistani authorities to help the public recognize stray radioactive material does little to inspire confidence, he adds. "It suggests that their ability to make sure they know where these sources are is not up to par."

"The worry is the lack of security of the Pakistani nuclear programme," says Jeffrey Lewis, director of nuclear strategy and non-proliferation at the New America Foundation in Washington DC. It is important to determine what the containers hold and where they came from, he adds.

The material has not been identified, but the PNRA states that it is a neutron source with low radioactivity and that such materials are commonly used in oil exploration. The site at which they were unearthed was used by a Soviet oil company until the late 
But accidental contamination could irretrievably spoil this potential ecosystem. Some contamination of the upper water layer is unavoidable when the lake is entered, says Sergey Bulat, a molecular biologist at the Petersburg Nuclear Physics Institute, where Vostok ice cores are being analysed, and where water probes will first arrive. "I don't believe the upper layer, which is basically glacier water, contains any life anyway," he says.

To attempt contamination-free sampling of the middle and bottom layers of the lake, Russian scientists plan to release a small robotic vehicle through the transportation module in the drilling device. The Russian Academy of Sciences is expected to approve funding of around US\$5 million for the 'hydrobot' programme.

Speculation about life in the virtually unexplored lake caught the attention of scientists and the public early on. But the discovery in the past few years of numerous other lakes beneath the Antarctic ice sheet, and of streams of subglacial water flowing rapidly between reservoirs, has deprived Lake Vostok of its unique status. Several proposals for drilling into moving water beneath the west Antarctic ice sheet are currently under review in the United States, for example.

"I'm not as stressed any more about Lake Vostok," says geologist Robin Bell, of Columbia University's Lamont-Doherty Earth Observatory in Palisades, New York. "It's still special, but it is reassuring to know that there are other subglacial environments we can preserve by not probing them at all." Quirin Schiermeier

1960s. "In the 1960s, there was no nuclear regulatory authority in the country," PNRA spokesman Zaheer Baig told Nature. "We think that when it was winding up its business, the oil company buried the source, covered in heavy shielding, for the public's safety." The detected radiation level from the sources is only "slightly higher than background", he adds.

If this is the case, the radiation levels from the containers will probably have been relatively harmless, says Matthew Bunn, a non-proliferation expert at Harvard University. "Sources of modest size are used in the oil industry all over the world, and it is not unusual to find that someone tries to save money by disposing of them improperly," he says. "It is yet another indicator, however, of the need for better cradle-to-grave tracking and control of radiological sources all over the world." Zeeya Merali

\section{Autism study panned by critics}

The leading US government funder of autism research is drawing fire over its proposal to run a randomized clinical trial of a treatment widely viewed by experts to be useless and potentially harmful, but that is broadly used for autism.

Chelation therapy, in which agents such as dimercaptosuccinic acid (DMSA) are used to bind metal ions in the blood so that they can be excreted easily, is an approved treatment for heavy-metal poisoning. Parents are using such therapy on children with autism because of their belief — which has been scientifically discredited - that mercury from vaccinations caused their children's condition.

In May, investigators at the US National Institute of Mental Health (NIMH) in Bethesda, Maryland, won approval from the US Food and Drug Administration to use DMSA in a trial of children with autism who are aged four to ten years and have detectable, but not toxic, levels of mercury or lead in their blood. The trial, 'Mercury Chelation to Treat Autism', is now under ethics review and has not enrolled any patients.

Critics say the trial will put children at risk for what is certain to be no medical gain. The American Academy of Pediatrics has concluded that there is no justification for giving children DMSA in the absence of very high levels of heavy-metal exposure, notes epidemiologist Ellen Silbergeld of the Johns Hopkins Bloomberg School of Public Health in Baltimore, Maryland. "I don't know why we have to do this experiment again on children."

Louis Cooper, a vaccine expert and former president of the American Academy of Pediatrics, says that despite a growing scientific consensus that mercury in vaccines does not cause autism, many parents still think that it is a problem. He says that a welldesigned study of chelation in children with autism would "respond to these parents' deeply held beliefs in the most careful, ethical way". Cooper explains that, with informed consent, such a study could ensure that the only families to be enrolled would be those already determined to try chelation.

Others argue that the study doesn't make scientific sense because autism has not been documented as a symptom of high-dose mercury poisoning and that, even if it were, the damage that mercury does to cells is



Some parents blame their children's autism on mercury in vaccines.

permanent and not reversible; chelation simply prevents additional harm. They say that the NIMH is bowing to political pressure because a growing number of parents with children who have autism use chelation therapy or want to use it. NIMH director Tom Insel denies pandering to families and says that the idea for the study "came up in the first place because we were getting reports that this was a therapy in broad use and there were very substantial questions about both its efficacy and its safety".

Because chelators bind indiscriminately to metal ions, they can deplete the body of essential metals such as copper, zinc, selenium and calcium. In ortersville, Pennsylvania, in 2005, a 5-yearold boy with autism died from cardiac arrest after being injected with a chelation agent. (The proposed study uses an oral agent.)

Recruitment for the study, initially proposed in 2006 by Susan Swedo, who heads autism research at the NIMH, was put on hold and additional review undertaken after a report in February 2007 showed that chelating agents could cause cognitive problems in rats (D. Stangle et al. Environ. Health Perspect. 115, 201-209; 2007).

Last week Insel said that because the study involves children, carries more than minimal risk and offers no demonstrable benefit to the participants, regulations dictate that it must be referred to a US Department of Health and Human Services panel for ethics approval.

Insel says that the study's in-limbo status shouldn't be read as its demise. "It hasn't been killed by any means. There's certainly a possibility that this project will go forward." Meredith Wadman

GOT A NEWS TIP?

Send any article ideas for Nature's News section to newstips@nature.com 